\title{
Metalinguistic Negotiations and Two Senses of Taste
}

\author{
- David Bordonaba-Plou -
}

\begin{abstract}
This paper defends the claim that the traditional Kantian division between two different types of judgments, judgments of personal preference (subjectively valid) and judgments of taste (intersubjectively valid), does not apply to some contexts in which metalinguistic negotiations take place. To begin, I first highlight some significant similarities between predicates of personal taste and aesthetic predicates. I sustain that aesthetic predicates are gradable and multidimensional, and that they often produce metalinguistic negotiations, characteristics that have motivated an individual treatment for predicates of personal taste. Secondly, contrary to Kant's claim, I maintain that there are cases where judgments of personal preference are intersubjectively valid; in some contexts of metalinguistic negotiation, judgments of personal preference direct universality to a similar extent as judgments of taste. Some examples of real-life conversations will be presented to illustrate this point.
\end{abstract} Keywords: Predicates of personal taste, aesthetic predicates, superior senses, lower senses, Kant, gradability, multidimensionality, metalinguistic negotiation.

Published online: 5 January 2021

\section{Predicates of personal taste and aesthetic predicates: revisiting an old issue}

What is the true standard of taste? Is there a definitive way to settle our seemingly endless disputes about it? Why do we want to embark so frequently in discussions on these matters, when answers to these fundamental questions have proved elusive?

Historically, the concept of taste has mainly tried to capture two ideas. As Hopkins points out, taste is "the ability to judge the aesthetic and artistic aspects of works of art and nature, or (sometimes) whatever capacity or sensibility underlies that ability." ${ }^{1}$ This definition differentiates between two kinds of abilities: the ability to judge aesthetic characteristics in artworks, and one that sometimes serves as a basis for the first one. Hopkins identifies this second ability with common taste; that is, the kind of taste involved when we discuss, for example, whether artichokes are tasty, Space Balls is funny, or Cadaqués is quaint. He says that the first ability, the ability to judge aspects of artworks, is uncontroversial; however, the second ability is more contentious, since it often produces shrill debates such as those concerning the influence it has on the first

David Bordonaba-Plou Universidad de Valparaíso Instituto de Filosofía, Facultad de Humanidades y Educación Serrano 546, Valparaíso, Chile email: davidbordonaba@gmail.com

${ }^{1}$ Hopkins (2009): 554. 
ability. Following Hopkins, I shall interpret the term 'taste' in a similar manner, being possible to understand it in two different ways. Specifically, I will label the first ability or type of taste as 'aesthetic appreciation,' while the second will be labelled as 'personal preference.' Following Kant, I will refer to those judgements based on the first ability as 'judgments of taste,' while those based on the second ability will be referred to as 'judgments of personal preference.'

This paper defends the claim that the traditional Kantian division between judgments of taste and judgments of personal preference does not apply to some contexts of "metalinguistic negotiation"; 1 that is, to some contexts that "concern a distinctive normative question - how best to use a word relative to a context." 2 The specific ways in which this can happen vary from one context to another; it can be "a matter of resolving ambiguity, prescisifying a vague term, setting a contextual parameter, or in any other way determining how some antecedently indeterminate matter of meaning should be settled." 3

To achieve this, I will go through three clearly differentiated steps. First, I shall highlight certain similarities between "predicates of personal taste" ${ }^{4}$ and aesthetic predicates, ${ }^{5}$ focusing on two distinct similarities between them: i) predicates of personal taste and aesthetic predicates are gradable and multidimensional adjectives; ii) the speakers using these predicates often get involved in situations of disagreement, specifically in cases of "context disagreement" ${ }^{6}$ or "metalinguistic negotiation." 7 Next, I will show that, in some contexts of metalinguistic negotiation, we cannot draw a clear distinction between judgments of taste and judgments of personal preference. According to Kant, although the basis of both is subjective, the difference between the two lies in the fact that only judgments of taste are intersubjectively valid, because only judgments of taste aim to be universal. Judgments of taste are universal because all humans share similar cognitive abilities, and because they are not related to personal interest; as a result, when a judgment of taste is made, we can expect a similar judgment from everyone. On the other hand, judgments of personal preference do not aim to be universal, since they are not free from all personal interest; hence, it is not plausible to expect a similar judgment from the audience when someone makes a judgment of personal preference.

Contrary to this understanding, I will show that, in some contexts of metalinguistic negotiation, speakers who have made judgments of personal preference behave in a way that indicates they conceive their judgments as intersubjectively valid; in other words, there are cases of metalinguistic negotiation where judgments of personal preference are intersubjectively valid. Finally, I will provide some examples of real-life conversations to illustrate this last point.

\footnotetext{
Plunkett, Sundell (2013).

Ibidem: 3.

${ }^{3}$ Ibidem.

${ }^{4}$ Lasersohn (2005); MacFarlane (2014).

${ }^{5}$ Other authors prefer to speak of "aesthetic terms" (Kivy, 1973), "aesthetic concepts" (Sibley, 1956, 1965) or "aesthetic adjectives" (Liao, Meskin, 2017; McNally, Stojanovic, 2017). For this work, the distinction is not relevant, since the aim is to analyse the situations of metalinguistic negotiation produced when using this type of expressions.

${ }^{6}$ Sundell (2011).

7 See also Plunkett (2015); Sundell $(2016,2017)$.
} 
Before continuing, a qualification is in order to avoid possible misunderstandings. It is not my intention to determine how the evaluative force of the statements - including predicates of personal taste and aesthetic predicates - should be analysed. This question has been tackled in several debates by several authors; the debate around "thick and thin concepts" $^{8}$ is one of them. In aesthetics, this issue has also been extensively discussed; Sibley, for example, distinguishes between "intrinsically or solely evaluative terms," ${ }^{9}$ through which we attribute a value; "descriptive merit-terms," 10 through which we attribute a property; and "evaluation-added property terms,"11 through which we attribute a value and also a property. Instead of offering an in-depth analysis of this matter, I will focus on highlighting that predicates of personal taste and aesthetic predicates are gradable and multidimensional, and that they often produce metalinguistic negotiations, while also focusing on what happens when speakers engage in this type of negotiation.

The paper, therefore, will be laid out as follows: in section two, I will examine the two different senses of taste from a historical perspective; then, I will show that, in a particular sense, an aesthetic dispute can be just a matter of personal preference. In section three, I will present and analyse two characteristics shared by both taste and aesthetic terms: gradability and multidimensionality. Later, in section four, I will show that, due to gradability and multidimensionality, speakers often get involved in metalinguistic negotiation situations. I will examine this notion, and then I will present some real-life examples of discussions where judgments of personal preference produce metalinguistic negotiation. I will show that, in some instances, judgments of personal preference aim to be universal and, therefore, intersubjectively valid, just as it is with judgments of taste. Finally, in section five, I will draw some conclusions.

\section{Two senses of taste: aesthetic appreciation and personal preference}

As mentioned in the Introduction, there are two different ways in which we can understand the term 'taste': as aesthetic appreciation, or as personal preference. Judgments based on aesthetic appreciation - that is, judgments of taste - are judgments such as 'Rothko's No. 6 is beautiful,' 'I love the Rothko's work,' or 'John Steinbeck is a much better writer than Dan Brown.' Judgments based on personal preference - that is, judgments of personal preference - are judgments such as 'Artichokes are tasty,' ‘I love turkey meat,' or 'Airplane! is much funnier than Space Balls.'

To give a preliminary analysis of both types of judgments, we must note first their similarities and differences. According to Kant, the basis of both types of judgment is a subjective feeling; on the one hand, it is a feeling because judgments of personal preference and judgments of taste are not cognitive judgments, and both originate from a feeling of pleasure or displeasure. This feeling, on the other hand, is subjective because it "is a feeling which the subject has of itself and of the manner in which it is affected by the representation."12

\footnotetext{
${ }^{8}$ See Williams (1985); Kirchin (2013).

9 Sibley (2001): 91.

${ }^{10}$ Ibidem: 91.

${ }^{11}$ Ibidem: 92.

12 Kant (2007): 35.
} 
However, judgments of taste and judgments of personal preference can also be very different in other aspects. The latter are subjectively valid, while the former, following the Kantian tradition in aesthetics, are intersubjectively valid; judgments of taste, unlike judgments such as 'artichokes are tasty,' strive for universality. This universality is founded on two factors: one, all humans share the same cognitive faculties, so, if I assess an artwork as beautiful, I can expect a similar observation from someone else, since we share very similar cognitive faculties. Two, judgments of taste - unlike judgments of personal preference - are free from all personal interest; as such, we should have reasons to expect the same delight and, therefore, a similar judgment in every other person. We could rephrase this idea under the philosophy of language, indicating that aesthetic predicates are "high-pressure terms," while predicates of personal taste are "low-pressure terms." ${ }^{13}$ Aesthetic predicates, therefore, are terms through which speakers put higher pressure on the audience, and hence receive their agreement; while predicates of personal taste are terms through which speakers put a lower pressure on the audience.

The two senses of taste are interrelated, but the connection has been presented differently in various historical times and debates. In this section, I will present a brief historical analysis of the evolution of the distinction, proposing that, contrary to what is supported in the aesthetic tradition, an aesthetic dispute can just be a matter of personal preference.

\subsection{The hierarchy of the senses: a brief historical analysis}

To correctly understand the distinction between personal preference and aesthetic appreciation, we need to look back to Ancient Greece, where philosophers drew a distinction between two different kinds of senses: the superior senses, sight and hearing, and the lower senses, touch, smell and taste. Plato, one of the oldest traceable sources of the distinction, says:

This is the sort of thing I mean: do sight and hearing afford men any truth or aren't even the poets always harping on such themes, telling us that we neither hear nor see anything accurately? And yet if these of all bodily senses are neither accurate nor clear, the others will hardly be so; because they are, surely, all inferior to these. ${ }^{14}$

This distinction sets the basis for drawing another important distinction: between the beautiful, which can only be perceived by the senses of sight and hearing; and the pleasant or agreeable, which can be perceived by the other lower senses. ${ }^{15}$ By the end of the $18^{\text {th }}$ century, the idea that aesthetic appreciation could only be achieved by the superior senses was a fairly consolidated one: "Consequently the sensuous aspect of art is related only to the two theoretical senses of sight and hearing, while smell, taste, and touch remain excluded from the enjoyment of art."16

\footnotetext{
${ }^{13}$ Sundell (2017).

14 Plato (2002): 9-10.

${ }^{15}$ See Kosmeyer (1999): 24, (2007): 146; Sweeney (2007): 117.

${ }^{16}$ Hegel (1988): 38.
} 
Through this period, the link between these two kinds of taste was defined within metaphorical terms. Thinkers of the time often made analogies between the lower and the higher senses to understand the relation between these two kinds of taste: "We metaphorically apply the idea of sweetness to sights, and sounds"; 17 "We often apply the quality of sweetness, metaphorically, to visual objects." 18

It was Kant who broke away from the idea of the metaphorical resemblance between aesthetic appreciation and personal preference, setting the term 'taste' only for the former. To illustrate this point, consider the next passage:

It is quite plain that in order to say that the object is beautiful, and to show that I have taste, everything turns on what I make of this representation within myself, and not on any factor which makes me dependent on the existence of the object. Everyone must allow that a judgment on the beautiful which is tinged with the slightest interest, is very partial and not a pure judgment of taste. ${ }^{19}$

For Kant, judgments of personal preference and judgments of taste are different. One necessary requisite for a judgment to express people's taste is to be free of all personal interest. Although, as I have noted before, both judgments are based on a subjective feeling, the delight present in judgments of personal preference is "determined not merely by the representation of the object [as in judgments of taste], but also by the represented bond of connexion between the subject and the existence of the object." 20 When we eat or drink something, both nourishment and our own pleasure are involved; conversely, judgments expressing our aesthetic appreciation are said to be free from all personal interest. Therefore, judgments expressing our personal preferences - for example, gustatory preferences - are not judgments of taste because they are based on self or personal interest.

To Kant, therefore, judgments expressing our aesthetic appreciation are judgments of taste precisely because they are free from all personal interest. Unlike judgments of personal preference where a dependency does exist between the experiencing subject and the experienced object, "the judgment of taste is simply contemplative." ${ }^{21}$ This idea has been one of the focal points of aesthetics since Kant. Frank Sibley, one of the most influential authors on contemporary aesthetics, makes a similar remark:

When I speak of taste in this paper, I shall not be dealing with questions which center upon expressions like "a matter of taste" (meaning, roughly, a matter of personal preference or liking). ${ }^{22}$

Sibley distinguishes between matters of personal preference and aesthetic appreciation, the latter being an ability to notice or detect certain things that are relevant to making

\footnotetext{
17 Burke (1990): 113.

18 Ibidem: 140.

19 Kant (2007): 37.

${ }^{20}$ Ibidem: 41.

21 Ibidem.

22 Sibley (1959): 423.
} 
a given judgment of taste. Sibley's idea, then, was the same Kant proposed: aesthetic issues are not just a matter of personal preference.

\subsection{Can an aesthetic appreciation be just a matter of personal preference?}

Kant's and Sibley's remarks have a clear consequence: aesthetic issues are entirely different from questions of personal preference. Discussing if artichokes are delicious or not, for instance, is drastically different from discussing if Picasso's Guernica is a great painting or not. For the latter, we need to take into consideration a bigger range of opinions, those of artists or art critics; to consider only our personal opinion does not seem to be enough. If I say Picasso's Guernica is bad art, founding my judgment solely on my personal disliking of the painting, many people may regard my observation as mistaken. Contrariwise, in deciding if artichokes are delicious or not, my personal like or dislike of it might be all we need to take into account; besides, we can expect a bigger general agreement in the case of the Guernica, rather than in the case of the artichokes. Let us not forget: judgments of taste, contrary to judgments of personal preference, aim to be universal.

Consequently, disagreements involving predicates of personal taste - for example, on culinary issues - are commonly described as "faultless disagreements," ${ }^{23}$ while it is more controversial to regard an aesthetic dispute as such. Predicates of personal taste and aesthetic predicates are, therefore, different, because the former are low-pressure terms, while the latter are deemed high-pressure terms. As Sundell says: "the preponderance of theories in the literature on predicates of personal taste lend themselves perfectly to the low-pressure terms"; ${ }^{24}$ that is, predicates of personal taste place low-pressure on the audience, while aesthetic predicates put high-pressure on the audience to agree with our statement. Thus, predicates of personal taste create disagreements that are just matters of personal preference - hence faultless - whereas aesthetic predicates give rise to substantive or genuine disputes.

However, if aesthetic predicates and predicates of personal taste are so different, it should be hard to find cases where an aesthetic dispute were a matter of personal preference. To phrase it differently, it should be challenging to find situations where both judgments were easily confused. In section four, I will show that there are cases of metalinguistic negotiation where judgments of personal preference are intersubjectively valid. However, for the remainder of this section, I will focus on another type of situation in which it may be difficult to distinguish between the two types of judgments, specifically on those cases where an aesthetic dispute can be described as a matter of personal preference.

\footnotetext{
${ }^{23}$ Some authors have rejected the very possibility that such disagreements exist, for example, Stojanovic (2007); Buekens (2011); Rovane (2012). However, many others have tried to accommodate the phenomenon by developing theories explicitly designed for such a task, for example, Kölbel (2003); Glanzberg (2007); MacFarlane (2007), (2014); Egan (2014); Kompa (2016); Wyatt (2018).

${ }^{24}$ Sundell (2017): 85.
} 


\subsection{Some aesthetic disputes are just matters of personal preference}

Although Sibley speaks of matters of personal preference, he fails to analyse the relation between the two different senses of taste. Peter Kivy explicitly reports this refusal: "It is important, I think, for us to give this concept of taste [De gustibus] our careful scrutiny, despite Sibley's disclaimers." 25 There have been some authors, however, that have taken the connection seriously, Hume being one of them:

Whoever would assert an equality of genius and elegance between Ogilby and Milton, or Bunyan and Addison, would be thought to defend no less than an extravagance, that if he maintained a mole-hill to be as high as Teneriffe, or a pond as extensive as the ocean. Though there may be found persons, who give the preference to the former authors; no one pays attention to such a taste; and we pronounce, without scruple, the sentiment of these pretended critics to be absurd and ridiculous. The principle of the natural equality of tastes is then totally forgot, and while we admit it on some occasions, where the objects seem near an equality, it appears an extravagant paradox, or rather a palpable absurdity, where the objects so disproportioned are compared together. ${ }^{26}$

For Hume, claiming the works of John Ogilby and John Milton are similar in value would be a complete absurdity. In fact, that would be as absurd as saying that a pond is the same size as the Pacific Ocean, or that a molehill is as big as the Teide mountain in Teneriffe. As Hume says, when the objects seem to be at odds in aesthetic value, the principle of the equality of taste is at stake. In those cases, an aesthetic appreciation can be just a matter of personal preference; in other words, if two speakers are engaged in an aesthetic dispute, but they are praising objects - artworks or persons, for example - that are very similar in aesthetic value, then we can say that their disagreement is faultless. Consider the next conversation between Albert and David:

(1) Albert: F. Scott Fitzgerald is the best American writer of the $20^{\text {th }}$ century.

(2) David: No, John Steinbeck is the best American writer of the $20^{\text {th }}$ century.

In view of (1) and (2), it would be okay for Layla to say:

(3) Layla: Your discussion is just a matter of taste.

It can be said that the dispute is just a matter of personal preference because both speakers praise objects that are very similar in aesthetic value; however, if the objects were very different in aesthetic quality, then the dispute would not be a matter of personal preference. Consider the following exchange between Albert and David:

\footnotetext{
${ }^{25}$ Kivy (1973): 32.

${ }^{26}$ Hume (1816): 260-261.
} 
(4) Albert: F. Scott Fitzgerald is the best American writer of the $20^{\text {th }}$ century.

(5) David: No, Dan Brown is the best American writer of the $20^{\text {th }}$ century.

On this occasion, it would not be okay for Layla to say:

(6) Layla: Your discussion is just a matter of taste.

The dispute now seems a genuine disagreement, where one party, David, is mistaken. It could be argued that there are no reasons to support this claim, because David's opinion in considering Dan Brown the best American writer of the $20^{\text {th }}$ century is as legitimate as Albert's opinion in considering F. Scott Fitzgerald as the best American writer of the $20^{\text {th }}$ century. However, I believe that is not the case; not only would the literary scholars and critics around the world consider this blatantly false, but many people would be inclined to agree with their view as well.

In essence, when two speakers praise objects that are similar in aesthetic value, the Latin dictum De gustibus non est disputandum seems to also apply to aesthetic disputes. To put it differently, in these cases we cannot draw a clear distinction between two different types of taste, because judgments of taste have become a simple matter of personal preference. As Kivy states: "the reasons on one side can be expected to balance the reasons on the other; and hence to fall on one side of the argument or the other can only be the result of inclination... merely a matter of taste." 27

In sum, when speakers praise objects with similar aesthetic value, an aesthetic dispute can be just a matter of personal preference. Even so, one might object that this is not enough to indicate that there are situations where the two senses of taste are indistinguishable. Although the discussion between David and Albert in (1)-(2) can be described as a matter of taste, it is a case of aesthetic appreciation. To illustrate the basis of the idea presented in this paper, it needs to be shown that a judgment of personal preference - for example, a culinary judgment - can be intersubjectively valid. That will be explored in section four, where it will be shown that this happens in some contexts of metalinguistic negotiation.

Before explaining what a metalinguistic negotiation is, we first need to characterise two prominent features of aesthetic adjectives. I will contend that aesthetic adjectives, just as predicates of personal taste, are gradable and multidimensional, and that these features are responsible for metalinguistic negotiation.

\section{Aesthetic predicates: gradability and multidimensionality}

Several authors ${ }^{28}$ have argued that predicates of personal taste and aesthetic predicates are gradable adjectives. Typical gradable adjectives such as 'tall' or 'rich' are said to be functions from individuals to degrees in a scale. For example, saying that Robert is rich is saying that Robert is as rich as, or even richer than a contextually determined point in

\footnotetext{
${ }^{27}$ Kivy (1973): 34.

${ }^{28}$ See Glanzberg (2007); Sundell (2016); McNally, Stojanovic (2017); Liao, Meskin (2017).
} 
a wealth scale. Conceivably, Robert could be rich in many common contexts if he has at least half a million dollars in the bank; but in a setting of a meeting of billionaires, Robert would not be considered rich for having that amount of money. Similarly, saying that Robert is tall is saying that Robert is as tall as, or even taller than a contextually determined point in a tallness scale. If, for instance, Robert is, say, 1.80 metres tall, he would be tall within a common context; he would not be considered tall, however, if he were part of a basketball team. In the same way, saying that a town is quaint, or that a performance is graceful, is saying that the town you are visiting is at least as quaint as a contextually determined point on a quaintness scale, or that the performance is at least as graceful as a contextually determined point on a gracefulness scale.

Moreover, predicates of personal taste and aesthetic predicates are multidimensional. ${ }^{29}$ Unlike unidimensional adjectives such as 'tall, ' old,' or 'new,' adjectives such as 'tasty,' 'quaint,' 'beautiful,' or 'graceful' are multidimensional. In short, multidimensional adjectives are those that involve several dimensions, which are relevant for saying that a given noun holds the attribute referred to by the adjective. Thus, a city can be large if one takes into account its population; but it can also be large if observed from the perspective of its geographical extension. As a result, both population and extension would be the relevant dimensions or criteria for saying that a city is large; hence, a city can be large in two different ways.

In the two sections which follow, I will explain these two features in some depth to bring into view the basis for understanding them, since they are the cause of metalinguistic negotiations.

\subsection{Gradability}

Gradable adjectives are measure functions; that is, functions from objects or individuals to points in a scale. As my basis I follow Kennedy's analysis of gradable adjectives. According to Kennedy, the positive form of gradable adjectives - for example, in sentences like 'Robert is tall' - has a "null morpheme [called pos] that has the same semantic function as overt degree morphology." ${ }^{30}$ The formal rendering of the meaning of pos is:

$$
\text { (7) }[p o s]=\lambda g \lambda x \cdot g(x) \geq \mathbf{d}_{\mathrm{s}}
$$

where $g$ refers to a gradable adjective, $x$ to an individual, and $\mathbf{d}_{\mathrm{s}}$ to the contextually appropriate standard of comparison. Then, the meaning of pos can be paraphrased in the following way: being a gradable adjective, say, tall, and an individual, say, Peter, Peter is at least as tall as the contextually appropriate standard of comparison.

Gradable adjectives are typically described as saying that the truth conditions for the statements that include them vary from context to context. Consider the next sentence:

(8) Space Balls is a good movie.

${ }^{29}$ See Cepollaro, Stojanovic (2016); McNally, Stojanovic (2017).

${ }^{30}$ Kennedy (2007): 7. 
This statement can be true in some contexts, but false in others. "One way to account for this variation is to characterise the truth conditions of such predicates in terms of a contextually defined STANDARD OF COMPARISON." ${ }^{31}$ Until we know the contextually appropriate standard of comparison, we cannot say if the proposition expressed by an utterance of (8) is true or false. If the standard of comparison is high - e.g., a movie is deemed good if it has at least eight points in the IMDb rating scale - then (8) is false. However, if the standard of comparison is low - e.g., a movie is deemed good if it has at least 5 points in the IMDb rating scale - then (8) is true.

However, the standard of comparison "is itself determined relative to a COMPARISON CLASS." 32 To put roughly, a movie can be a good movie if we are talking about it within the contexts of the greatest masterpieces of the history of cinema; but a movie can also be good if we watch it just to pass the time. The contextually appropriate standard of comparison will depend on the comparison class, since the standard will vary accordingly. For instance, if the comparison class is the best cinema classics, then the standard of comparison will undoubtedly be very high, and (8) will be false. However, if the comparison class for saying that a movie is good is whatever movie you can see to pass the time, the standard of comparison will be probably low, and (8) will be true.

The counterparts of these measure functions in natural languages are specific linguistic expressions. I follow Kennedy's list of linguistic criteria for identifying gradable adjectives. First, they occur felicitously in comparative clauses:

(9) Do you see how much more beautiful nature is on your side of the road?

(10) I am also glad Master Thomas, you are now as beautiful as ever in your new full Gray coat.

Second, they are compatible with degree modifiers such as 'very' or 'quite':

(11) We have very beautiful flowing Kingdom songs of all kinds.

(12) The result is quite beautiful and the children will have a piece of art they are proud to display.

Third, they are compatible with sufficiency morphemes such as 'so' or 'too':

(13) So beautiful and so much more melancholy with the harp.

(14) Love the packaging also, it's too beautiful.

Fourth, they are consistent with the question word 'how':

(15) Sam looked up at the starlit sky and smiled softly at how beautiful it was.

(16) There are no words to describe just how beautiful this cover is.

\footnotetext{
${ }^{31}$ Kennedy, McNally (2005): 348.

32 Ibidem: 349.
} 
All the examples listed above were taken from the Corpus of Contemporary American English. ${ }^{33}$ Taking a closer look to the absolute frequencies of the modifiers that appear more frequently with 'beautiful,' we can see that Kennedy's list is by no means arbitrary: 'most' (98628 occurrences), 'so' (32298 occurrences), 'more' (23158 occurrences), 'very' (21586 occurrences), and 'how' (14575 occurrences), are the five most common modifiers of the adjective 'beautiful.' All of them are on Kennedy's list. Therefore, taking into consideration both the theoretical and empirical data, it can be accordingly concluded that aesthetics adjectives such as 'beautiful' are gradable.

\subsection{Multidimensionality}

In addition to being gradable, predicates of personal taste and aesthetic predicates are multidimensional. A unidimensional adjective is "one for which exactly one criterion is used to order individuals according to the property it describes"; ;4 for example, to properly order two objects that are heavy, you only need to know what their weights are. In contrast, a multidimensional adjective is one for which more than one criterion can be used to order individuals; something can be called 'quaint,' or 'graceful' depending on different features. For instance, a town can be quaint if it has antique stores, if their restaurants offer regional gastronomy, or if the town has unique sightseeing places. Similarly, a ballet performance can be graceful if the dancer mixes right balance with high power and energy, or if the dancer makes perfect curved track movements.

Speakers can select different contextually determined features or dimensions upon which assess the quaintness of the town, or the gracefulness of the performance. Note that the contextual restriction of the dimensions that are relevant for making a given judgment is bigger in the case of predicates such as 'graceful' or 'quaint,' than in the case of other more evaluative predicates such as 'tasty' or 'beautiful.' As said in the Introduction, it is not my intention to investigate the evaluative character of predicates of personal taste and aesthetic predicates. Nonetheless, the following can be said: the thicker the term, the less variability should be expected from context to context on the particular dimensions selected. Predicates such as 'quaint' or 'graceful' are thick concepts and, as such, have certain descriptive meaning attached to them. Something is quaint if it is unusual and old-fashioned, and something is graceful if it is subtle, thin, or small; this descriptive meaning is going to restrict, to some extent, the number of dimensions or criteria that could potentially be relevant. Concurrently, thin concepts such as 'tasty' or 'beautiful' have no descriptive meaning attached to them, as attested by the fact that common dictionary definitions of these terms often include other thin concepts such as 'good,' 'excellent,' 'pleasant,' 'appealing,' or 'attractive.' 35

${ }^{33}$ More info: https:/ / corpus.byu.edu/coca/. Accessed 17 Jul 2019. Similar results are obtained with other aesthetic predicates and with different predicates of personal taste.

${ }^{34}$ McNally, Stojanovic (2017): 20.

${ }^{35}$ The Oxford English Dictionary defines 'tasty' as follows: "1. (of food) having a pleasant, distinct flavour; 2. Very attractive or appealing." (see https://en.oxforddictionaries.com/definition/tasty). And defines 'beautiful' as follows: " 1 . Pleasing the senses or mind aesthetically; 2 . Of a very high standard; excellent." (see https://en.oxforddictionaries.com/definition/beautiful). 


\subsection{Gradability and multidimensionality: a cause of metalinguistic negotiation}

As stated above, aesthetic predicates, just as predicates of personal taste, are gradable and multidimensional. I have also noted earlier that these features are the cause of metalinguistic negotiations. Consider the following conversation:

(17) Layla: Rothko's Orange and Yellow is beautiful.

(18) David: No, Rothko's Orange and Yellow is not beautiful.

In (17) and (18), Layla and David disagree whether Orange and Yellow, a painting by Mark Rothko, is beautiful or not. This disagreement begins with the application of an aesthetic predicate, and this application can produce, ultimately, a disagreement that depends on two different features of the aesthetic predicate: i) which dimensions speakers select as relevant for the application, linked with multidimensionality; and ii) the standards of comparison of each dimension, ${ }^{36}$ linked with gradability.

Consequently, four scenarios are possible: i) speakers disagree on all of the dimensions; ii) speakers agree on all of the dimensions but disagree on the standards of one or more of the dimensions; iii) speakers disagree on some dimensions, agree on other, and agree on the standards of the dimensions on which they agree; and iv) speakers disagree on some dimensions, agree on other, but disagree on one or more of the standards of the dimensions on which they agree. ${ }^{37}$

In the first scenario, speakers can disagree on all the dimensions that are relevant for saying that a painting is beautiful. Suppose that, for Layla, the dimensions that are relevant are technical expertise, abstraction, and innovative capacity; but for David the dimensions that are relevant are more related with the figurative aspects of painting, such as imitation and symmetry.

For the second alternative, both speakers can agree on all the dimensions, but disagree on one or more of the contextually appropriate standards of comparison. In this case, Layla and David might agree on the dimensions that are relevant for saying that a painting is beautiful - say, technical expertise, abstraction and innovative capacity but they disagree because their standards of at least one of them are very different. For David, a painting could be beautiful if it has at least a 9 on a 10-point scale in technical expertise, and a 6 in abstraction and innovative capacity; Layla, then, raises the bar a little higher, demanding a 9 on each category. Within this context, David would deem Rothko's painting beautiful, but Layla would not, even though they both used the same dimensions for saying that the painting is beautiful.

For the third option, speakers disagree on some dimensions but agree on other, and they agree on the standards of the dimensions on which they agree. Suppose that David believes that a painting should be dynamic, while Layla thinks that it should be

\footnotetext{
${ }^{36}$ For the sake of simplicity, I am only considering here the standards of comparison.

${ }^{37}$ Another option is logically possible: speakers agree on the standards of the dimensions on which they disagree. However, this option makes no sense; speakers can agree on the standards of the dimensions on which they agree, but not vice versa, since this would imply an agreement on the standards of non-commensurable dimensions.
} 
provocative. Although they disagree on these dimensions, they agree in considering that a painting is beautiful if it shows technical expertise; moreover, they agree on the extent to which it should show technical expertise. In this case, the disagreement will be due to the dimensions on which the speakers do not agree.

Finally, speakers disagree on some dimensions but agree on others, but they disagree on the standards of the dimensions on which they agree. Suppose that Layla thinks that a painting should be innovative and provocative, but David thinks that it should be figurative and symmetric; although they disagree on these dimensions, they agree in thinking that a painting should show technical expertise to be considered beautiful. However, they also disagree on the contextually appropriate standard of this latter dimension; in this case, their disagreement would be based both on the dimensions they do not agree with and the contextually appropriate standard of the dimension they agree on. In the end, they could negotiate both the dimensions and the standard.

To recapitulate, as in the case of judgments of personal preference, judgments of taste can imply metalinguistic negotiations. That is, scenarios that concern a question on how best to use a word relative to a context, determining what dimensions and/or standards of comparison are relevant.

In the next section, I will present several examples where people engage in metalinguistic negotiation after making judgments of personal preference, specifically culinary judgments. I will show that, although sometimes speakers behave indicating that their judgments of personal preference are only subjectively valid, they could also behave in a way that indicates that their judgments of personal preference are intersubjectively valid. Then, I will draw the implications this has for aesthetics, specifically those concerning the distinction between the two different senses of taste.

\section{Metalinguistic negotiations and judgments of personal preference}

Metalinguistic negotiation is the first step for a judgment of personal preference to be considered intersubjectively valid. When I expose the dimensions that are relevant to making my judgment, I am presenting the criteria supporting my judgment; I can do so by attempting the other party to either accept these criteria or not. Claiming that any context of metalinguistic negotiation, where judgments of personal preference are involved, is a context in which the speakers try to make the other party accept their respective judgments, is not the idea defended in this work.

In negotiating, speakers can present what are the relevant criteria for making their judgments of personal preference; they put forth the dimensions and/or standards of comparison that are relevant for them, but with no intention of the other party accepting such dimensions and/or standards. In other words, they exert low pressure on the other party to accept their stance; in Kant's words, they behave as if their judgments were subjectively valid. When speakers realize that their criteria are different, they can move "from 'Oh yes/Oh no' dialogue to 'Ok/Ok' dialogue." ${ }^{38}$

\footnotetext{
${ }^{38}$ Stojanovic (2007): 694.
} 
However, as I will show below, there can be cases where the participants will try for the other party on the discussion to recognize and accept their stance, accepting the dimensions and/or standards they think are important, thus exerting high pressure on the audience to agree with them. As Kant stated, in those cases people behave in a way that indicates their judgments of personal preference are intersubjectively valid.

\subsection{Everyday examples of intersubjectively valid judgments of personal preference}

The central purpose of the Kantian distinction between judgments of personal preference and judgments of taste, was not to analyse particular cases but rather to determine the conditions of possibility of judgments of taste. The purpose of this work is different, for its focus is to show that there are particular situations where speakers make judgments of personal preference but conceive them as intersubjectively valid. The methodology used will be different from the one used by Kant and traditional aesthetics, since the current study is halfway between the philosophy of language and aesthetics.

The negative program ${ }^{39}$ in experimental philosophy of language has highlighted the problems of using made-up examples. For them, the "method of cases," 40 the methodology traditionally used in philosophy of language, has a serious problem: we cannot conclude general theses about linguistic phenomena from cases where the only intuitions that are considered are those of the author. Consequently, on this section, I will present examples of real-life conversations that took place online, in which people engage in metalinguistic negotiation when discussing culinary issues. I will present two cases: first, one where speakers make judgments of personal preference and their behaviour indicates that the judgments are subjectively valid; in other words, a low-pressure case. Then, a case where speakers make judgments of personal preference and their behaviour indicates that the judgments are intersubjectively valid; simply put, a high-pressure case.

Let us begin then with the low-pressure case. Consider the next excerpt from a Reddit conversation ${ }^{41}$ where people are discussing the subject of tacos and turkey meat:

(19) Yellnik: I thought I hated tacos too until I ate a taco that wasn't ground turkey with old El Paso seasoning in a hard shell.

(20) Teddy_Sanchez: Do you just not like the hard shells? I've never had any luck turning ground turkey into anything one would really want to do again. Beef ribs are expensive, but the best tacos I maybe ever had were smoked beef ribs.

(21) Iwgbot: I love ground turkey! It's a lean protein that's incredibly flexible. It's perfect for a stir-fry, and when combined with finely diced mushrooms the most delicious meatballs/meatloaf/ burgers are born.

\footnotetext{
${ }^{39}$ See Machery, Mallon, Nichols et al. (2004); Mallon, Machery, Nichols et al. (2009); Alexander, Mallon, Weinberg (2010).

${ }^{40}$ Mallon, Machery, Nichols et al. (2009): 338.

${ }^{41}$ https:// www.reddit.com/r/Cooking/comments/ginj0t/i_used_to_hate_pork_several_decades_later/. Accessed on 2 Jan 2021.
} 
(22) No_Ice_Please: Man, I love ground Turkey. Truthfully, nowadays I buy it over ground beef 9 times out of 10 unless it's for something specific. Turkey meatloaf, turkey burgers, turkey picadillo even. Maybe it's just your personal taste but most everything I make with it is great (to me).

(23) lionorderhead: It always feels dry to me. A turkey meatloaf crumbles and falls apart on the fork.

This conversation is a clear example of metalinguistic negotiation. People who like turkey meat remark on how flexible and healthy it is; people who do not like it, think that it lacks consistency, aside from being a very plain meat. However, despite the metalinguistic negotiation, nothing indicates that the participants expect a similar judgment from other commenters; furthermore, there are several reasons to conclude that people in this conversation are not trying to convince each other to accept their personal stance. There are a couple of linguistic marks to assert this: for starters, the use of the first person is constant, which indicates that the focus is not on the object being experienced, but on the subject having the experience. Some examples of this are: 'I've never had any luck,' ‘I buy it,' or 'I love ground turkey.' Then, there are several times in which participants use explicit marks of subjectivity; that is, linguistic marks involving the role of an experiencer. ${ }^{42}$ For example, 'your personal taste,' 'is great (to me),' or 'feels dry to me.'

Now, let us turn to the high-pressure case. Consider the next excerpts from an another discussion on Reddit ${ }^{43}$ on meatballs being better with or without breadcrumbs:

(24) original poster: Does anyone else not put bread crumbs or other fillers in their meatloaf, meatballs, similar? It's just the way my mom always made these kinds of dishes, she never added bread crumbs and other fillers to them. They don't fall apart either with egg. Still have spices and seasonings though. I'm just wondering if anyone else makes them this way.

(25) Trankebar: I do, and sometimes I don't. Usually I add it because it makes for more juicy meatballs, not because it acts as a filler. Pure meat meatballs can be very dense and chewy.

(26) Thisdude415: Meatballs and meatloaf really benefit from breadcrumbs. It soaks up all the juice that would otherwise leak out.

(27) Megzilla: The breadcrumbs help retain the juiciness and make them less dense.

(28) original poster: It doesn't fall apart without it so...? I guess it's optional.

(29) riverphoenixdays: I mean, most things are optional in cooking - it's about what you like to eat. That said, bread in meatballs is about texture and, most importantly, flavor.

(30) BossRedRanger: My mom never used bread crumbs either. Always juicy and tender meatloaf with nothing falling apart. Breadcrumbs just seems like what people are used to but unnecessary.

(31) original poster: Seems like it. I think they used to add it to increase amount, I think it originated during WW2. Anyways, that's what I was told.

\footnotetext{
42 See McNally, Stojanovic (2017): 24-25.

${ }^{43}$ https://www.reddit.com/r/Cooking/comments/9o0ytl/does_anyone_else_not_put_bread_ crumbs_or_other/. Accessed on 2 Jan 2021.
} 
The original poster opens the thread looking for support. She thinks breadcrumbs do not improve meatballs; they are optional because they only act as fillers. However, as the conversation goes on, many participants remark on the idea that adding breadcrumbs to meatballs is a must, since they are not fillers: they act as binders, making the mixture more consistent, as well as juicier. This is the opinion of Trankebar, Thisdude415, and Megzilla, for example. The original poster responds by saying that, since meatballs do not fall apart without breadcrumbs, putting them seems to be optional, at which point riverphoenixdays intervenes, acknowledging the original poster is right, as many things in the kitchen are optional, depending on what your tastes are. However, right after that, riverphoenixdays advises the original poster to use breadcrumbs in meatballs because doing so gives them a better taste. At the end of the conversation, BossRedRanger, who thinks, against the rest of the participants, that breadcrumbs are unnecessary, supports the original poster, effectively ratifying her on the original opinion that breadcrumbs are used only as fillers.

As seen in the example, people who think meatballs are better with breadcrumbs and people who think the opposite, engage in metalinguistic negotiation when they realize they view the matter differently. In doing so, they highlight the dimensions relevant to making appropriate judgments on the issue at hand, such as texture, juiciness, or taste; more importantly, they all behave, especially people who think that meatballs benefit from breadcrumbs, in a way that indicates that culinary judgments are intersubjectively valid. First, they try to sway the original poster's opinion through different observations, even when it seems that the original poster is only looking for some reaffirmation. Furthermore, the expressions they use, unlike in the low-pressure case, do not indicate that they conceive their judgments as only subjectively valid; there is no use of the first person, since the focus is on the experienced object, not on the person experiencing it. Examples of this are: 'Meatballs and meatloaf really benefit from breadcrumbs,' 'The breadcrumbs help retain the juiciness and make them less dense,' or 'bread in meatballs is about texture and, most importantly, flavor.'

Furthermore, there are no explicit marks of subjectivity. Besides, immediately after the reply in which someone explicitly states that culinary judgments are only subjectively valid, there is an attempt to convince the other party. Although at first riverphoenixdays recognizes that almost everything in cooking is optional because it depends on one's personal taste - indicating in this way that culinary judgments are subjectively valid - in the end, he or she tries to get the original poster to accept his or her stance, thus suggesting that this judgment of personal preference is intersubjectively valid.

In summary, there are cases of metalinguistic negotiation where the speakers expect a similar judgment from the audience. It can be said, then, that for all of them a culinary judgment - a judgment that, in principle, is only subjectively valid - ends up being a judgment of taste, an intersubjectively valid judgment.

\subsection{Aesthetic appreciation and metalinguistic negotiation: some consequences}

The main goal of this paper is to argue that the distinction between two senses of taste, aesthetic appreciation and personal preference, appears diluted in some cases of metalinguistic negotiation. If we recall Kant's insights, judgments of taste, that is, judgments 
expressing aesthetic appreciation, are different from judgments expressing personal preference, because the former but not the latter are free from all personal interest. Consider the following paragraphs in which Kant develops this idea:

For, since the delight is not based on any inclination of the subject (or on any other deliberate interest), but the judging subject feels himself completely free in respect of the liking which he accords to the object, ... he must regard it as resting on what he may also presuppose in every other person; and therefore he must believe that he has reason for expecting a similar delight from everyone. ${ }^{44}$

Many things may for him possess charm and agreeableness-no one cares about that; but when he declares something to be beautiful, he expects the same delight from others. $^{45}$

For Kant, judgments of taste are universal because they are intersubjectively valid since we all share the same relevant cognitive faculties. They are not based on personal interest, because someone who makes a judgment of taste has reasons to expect the same delight from another person. In contemporary terms, judgments of taste are intersubjectively valid because they include high-pressure terms, expressions that put high pressure on the audience to agree with the speaker. On the contrary, judgments of personal preference are only subjectively valid because they are based on personal interest, so someone who makes a judgment of personal preference does not have reasons to expect the same delight from another person. Thus, judgments of personal preference are only subjectively valid because they include low-pressure terms, expressions that put low pressure on the audience to agree with the speaker.

As seen on the examples, there are cases of metalinguistic negotiation where speakers behave according to the Kantian insight. However, there are other cases of metalinguistic negotiation where people behave differently, in a way that shows their judgments of personal preference aim to be universal; this becomes evident when speakers use certain distinct linguistic expressions. In cases where the speakers behave in a way that indicates their judgments of personal preference are only subjectively valid, there are constant references to the experiencing subject through the use of the first person and explicit marks of subjectivity. However, in cases where speakers behave in a way that indicates their judgments of personal preference are intersubjectively valid, neither of the linguistic criteria mentioned above is present; furthermore, the references are towards the experienced object, rather than the experiencing subject.

People that engage in metalinguistic negotiation and make judgments of personal preference, sometimes expect - and, in fact, may even demand - the same delight from the receiving party. In these cases, we cannot discern two different kinds of judgment, judgments of personal preference (only subjectively valid), and judgments of taste (intersubjectively valid). Therefore, in these cases, we cannot clearly discern two senses of taste, aesthetic appreciation and personal preference.

${ }^{44}$ Kant (2007): 43.

${ }^{45}$ Ibidem: 44. 


\section{Conclusions}

This paper defends the significant connection between disputes of taste and disputes of beauty. Predicates of personal taste and aesthetic predicates share, as we have seen, some distinctive features: both are gradable and multidimensional adjectives and can produce metalinguistic negotiations.

Even though this issue has been addressed before, not enough attention has been given to the distinctive metalinguistic features of aesthetic predicates. In section two I presented two different senses in which we can understand the notion of taste: personal preference and aesthetic appreciation. I also asserted a possible scenario where a certain aesthetic dispute can change into a matter of personal preference; as the objects or artworks praised by both speakers are close enough in aesthetic value, it seems plausible to say that aesthetic disputes can be just a matter of personal preference.

Later, in section three, I defended that aesthetic predicates and predicates of personal taste are gradable and multidimensional. I also maintained that these two features are responsible for the metalinguistic characteristics of aesthetic predicates. Then, in section four, I presented the notion of metalinguistic negotiation, by introducing two cases in which speakers engage in metalinguistic negotiation after making judgments of personal preference. On the first example, people behaved according to the Kantian insight, indicating that their judgments are subjectively valid; for the second case, the participants behaved in a way which indicated that their judgments of personal preference were intersubjectively valid. In short, there are cases of metalinguistic negotiation involving judgments of personal preference where judgments of taste and judgments of personal preference are indistinguishable; therefore, within this context, we cannot discern between aesthetic appreciation and personal preference.

Recently, an empirical cross-cultural study, ${ }^{46}$ based on the responses of more than 2000 people of 19 different countries, showed that people tend to think that judgments of taste are not intersubjectively valid. The fact that people sometimes regard their judgments of personal preference as intersubjectively valid is another strong indication against the idea that judgments of personal preference and judgments of taste are radically different.

\section{Acknowledgements}

This article has been elaborated in the framework of the project $A$ Computational Dynamic Analysis of Public Debates on Politics, Aesthetics and Taste, funded by CONICYT/FONDECYT/POSTDOCTORADO/N Proyecto 3180096. I am grateful to Nemesio García-Carril Puy and three anonymous referees for their fruitful comments. I am also grateful to the audience at the V Congreso Iberoamericano de Filosofía.

$\overline{46}$ Cova, Olivola, Marchery et al. (2018). 


\section{References}

Alexander J., Mallon R., Weinberg J.M. (2010), "Accentuate the Negative," Review of Philosophy and Psychology 1 (2): 297-314.

Buekens F. (2011), "Faultless Disagreement, Assertions and the Affective-Expressive Dimension of Judgments of Taste," Philosophia 39 (4): 637-655.

Burke E. (1990), A Philosophical Enquiry into the Origin of Our Ideas of the Sublime and Beautiful, Oxford University Press, New York.

Cepollaro B., Stojanovic I. (2016), "Hybrid Evaluatives: In Defense of a Presuppositional Account," Grazer Philosophische Studien 93 (3): 458-488.

Cova F., Olivola Ch.Y., Marchery E. et al. (2018), "De Pulchritudine non est Disputandum? A Cross-Cultural Investigation of the Alleged Intersubjective Validity of Aesthetic Judgment," Mind E Language 34 (3): 317-338.

Egan A. (2014), “There's Something Funny About Comedy: A Case Study in Faultless Disagreement," Erkenntnis 79 (1): 73-100.

Glanzberg M. (2007), “Context, Content, and Relativism,” Philosophical Studies 136 (1): 1-29.

Hegel G.W.F. (1988), Hegel's Aesthetics: Lectures on Fine Art, vol. I, T.M. Knox (ed.), Clarendon Press, New York.

Hopkins R. (2009), “Taste," [in:] A Companion to Aesthetics, S. Davies, K.M. Higgins, R. Hopkins et al. (eds.), Blackwell, Singapore: 554-556.

Hume D. (1826), "Of the Standard of Taste," [in:] The Philosophical Works of David Hume, vol. III, A. Black and W. Tait, Edinburgh: 256-282.

Kant I. (2007), Critique of Judgment, trans. J.C. Meredith, Oxford University Press, New York.

Kennedy C., McNally L. (2005), "Scale Structure, Degree Modification, and the Semantics of Gradable Adjectives," Language 8 (2): 345-381.

Kennedy C. (2007), "Vagueness and Grammar: The Semantics of Relative and Absolute Gradable Adjectives," Linguistics and Philosophy 30 (1): 1-45.

Kirchin S. (2013), "Introduction: Thick and Thin Concepts," [in:] Thick Concepts, S. Kirchin (ed.), Oxford University Press, Oxford: 1-19.

Kivy P. (1973), Speaking of Art, M. Nijhoff, The Hague.

Kölbel M. (2003), “Faultless Disagreement,” Proceedings of the Aristotelian Society 104 (1): 53-73.

Kompa N. (2016), "Faultless Disagreement, Context Sensitivity, and the Semantics of Evaluation," Grazer Philosophische Studien 93 (3): 396-418.

Kosmeyer C. (1999), Making Sense of Taste: Food and Philosophy, Cornell University Press, New York.

Kosmeyer C. (2007), "Delightful, Delicious, Disgusting," [in:] Food and Philosophy: Eat, Think and Be Merry, F. Allhoff, D. Monroe (eds.), Blackwell Publishing, Oxford: 145-161.

Lasersohn P.N. (2005), “Context Dependence, Disagreement and Predicates of Personal Taste," Linguistics and Philosophy 28 (6): 643-686.

Liao S., Meskin A. (2017), "Aesthetic Adjectives: Experimental Semantics and Context-Sensitivity," Philosophy and Phenomenological Research 94 (2): 371-398.

MacFarlane J. (2007), “Relativism and Disagreement,” Philosophical Studies 132 (1): 17-31.

MacFarlane J. (2014), Assessment-Sensitivity: Relative Truth and its Applications, Oxford University Press, New York.

Machery E., Mallon R., Nichols S. et al. (2004), "Semantics, Cross-Cultural Style," Cognition 92 (3): B1-B12. 
Mallon R., Machery E., Nichols S. et al. (2009), "Against Arguments from Reference," Philosophy and Phenomenological Research 79 (2): 332-356.

McNally L., Stojanovic I. (2017), "Aesthetic adjectives," [in:] Semantics of Aesthetic Judgments, J.O. Young (ed.), Oxford University Press, New York: 17-37.

Plato (2002), Phaedo, trans. D. Gallop, Clarendon Press, Oxford.

Plunkett D., Sundell T. (2013), "Disagreement and the Semantics of Normative and Evaluative Terms," Philosopher's Imprint 13 (23): 1-37.

Plunkett D. (2015), “Which Concepts Should We Use? Metalinguistic Negotiations and the Methodology of Philosophy," Inquiry: An Interdisciplinary Journal of Philosophy 58 (7-8): 828-874.

Rovane C. (2012), "How to Formulate Relativism," [in:] Mind, Meaning, and Knowledge: Themes From the Philosophy of Crispin Wright, A. Coliva, C. Wright (eds.), Oxford University Press, Oxford: 17-31.

Sibley F. (1959), "Aesthetic Concepts," Philosophical Review 68 (4): 421-450.

Sibley F. (1965), "Aesthetic and Nonaesthetic," Philosophical Review 74 (2): 35-159.

Sibley F. (2001), "Particularity, Art, and Evaluation," [in:] Approach to Aesthetics: Collected Papers on Philosophical Aesthetics, J. Benson, B. Redfern, J.R. Cox (eds.), Oxford University Press, New York: 88-103.

Stojanovic I. (2007), “Talking about Taste: Disagreement, Implicit Arguments, and Relative Truth," Linguistics and Philosophy 30 (6): 691-706.

Sundell T. (2011), "Disagreements about Taste," Philosophical Studies 155 (2): 267-288.

Sundell T. (2016), "The Tasty, the Bold, and the Beautiful," Inquiry: An Interdisciplinary Journal of Philosophy 59 (6): 793-818.

Sundell T. (2017), "Aesthetic Negotiation," [in:] Semantics of Aesthetic Judgments, J.O. Young (ed.), Oxford University Press, New York: 82-105.

Sweeney K.W. (2007), "Can a Soup Be Beautiful? The Rise of Gastronomy and the Aesthetics of Food," [in:] Food and Philosophy: Eat, Think and Be Merry, F. Allhof, D. Monroe (eds.), Blackwell Publishing, Oxford: 117-132.

Williams B. (1985), Ethics and the Limits of Philosophy, Taylor \& Francis, New York.

Wyatt J. (2018), "Absolutely Tasty: An Examination of Predicates of Personal Taste and Faultless Disagreement," Inquiry: An Interdisciplinary Journal of Philosophy 61 (3): 252-280. 